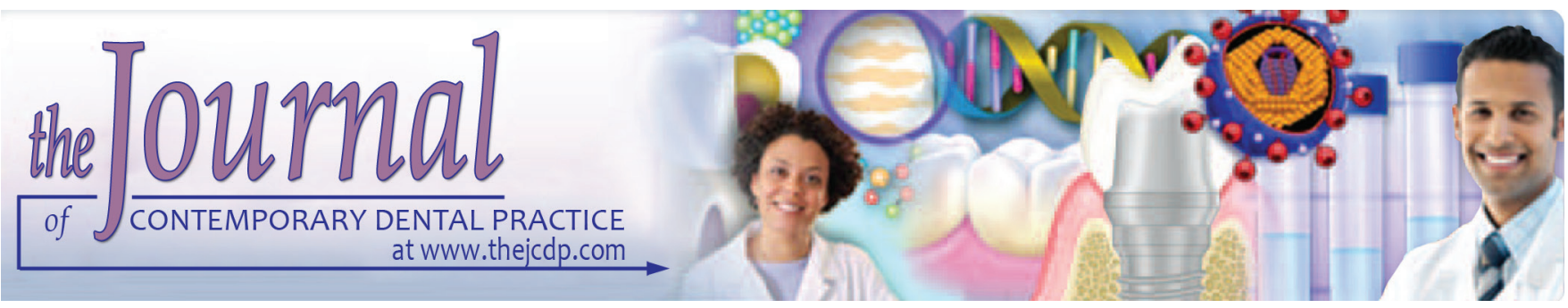

\title{
Comparison of Complications in Removable Mandibular Acrylic Splint and Cantilever Herbst for Management of Class II Malocclusion: A Retrospective Study
}

${ }^{1}$ RK Kanuru, ${ }^{2}$ Vinny Bhasin, ${ }^{3}$ Amit Khatri, ${ }^{4}$ KK Dodda, ${ }^{5}$ Era Singh, ${ }^{6}$ Shekhar Grover

\begin{abstract}
Introduction: Numerous appliances are present for the management of class II malocclusion. We have conducted a study to compare the clinical complications during treatment with either a removable mandibular acrylic splint (RMS) or with a cantilever Herbst (HC) appliance for the management of class II malocclusion.
\end{abstract}

Materials and methods: This study consisted of records of 114 patients (61 males, 53 females), who were divided into two groups. Group I received RMS and group II received $\mathrm{HC}$ for the treatment of class II, Division 1 malocclusion. They were further subdivided according to the telescopic system used [Dentaurum type I or propulsor mandibular abzil (PMA)] and fixation mode (splint with crowns or GripTite bands). Patients' clinical records were assessed to identify clinical complications.

Results: The results of the study showed that the incidence of complications during treatment in both groups was statistically nonsignificant. The complications with either crown or band were also statistically nonsignificant. The Dentaurum group showed more susceptibility to complications than the PMA group.

Conclusion: The PMA telescopic system is more efficient as compared with Dentaurum. Complication resulting from Herbst appliance is independent type of appliance used and mode of fixation.

\footnotetext{
${ }^{1,4}$ Department of Orthodontics and Dentofacial Orthopaedics Drs Sudha \& Nageswara Rao Siddhartha Institute of Dental Sciences, Chinaoutpalli, Gannavaram Mandal, Andhra Pradesh India

${ }^{2}$ Department of Orthodontics and Dentofacial Orthopedics Hitkarini Dental College, Jabalpur, Madhya Pradesh

${ }^{3}$ Department of Prosthodontist, Belconnen, Australian Capital Territory, Australia

${ }^{5}$ Department of Prosthodontics, Vokkaligara Sangha Dental College and Hospital, V. V. Puram, Bengaluru, India

${ }^{6}$ Public Health Dentistry, Maulana Azad Institute of Dental Sciences, New Delhi, India

Corresponding Author: Shehkar Grover, Public Health Dentistry Maulana Azad Institute of Dental Sciences, New Delhi, India Phone: +918109838589, e-mail: shhekhargrover@gmail.com
}

Clinical significance: Herbst appliance is the treatment of choice for class II malocclusion.

Keywords: Complications, Herbst appliance, Malocclusion.

How to cite this article: Kanuru RK, Bhasin V, Khatri A, Dodda KK, Singh E, Grover S. Comparison of Complications in Removable Mandibular Acrylic Splint and Cantilever Herbst for Management of Class II Malocclusion: A Retrospective Study. J Contemp Dent Pract 2017;18(5):363-365.

Source of support: Nil

Conflict of interest: None

\section{INTRODUCTION}

Angle, ${ }^{1}$ the "father of modern orthodontics," coined the term malocclusion that refers to misalignment or incorrect relation between the teeth of the two dental arches when they approach each other as the jaws close. Normal occlusion is when the mesiobuccal cusp of the upper first molar align with the buccal groove of the mandibular first molar. It is divided into class I malocclusion (neutrocclusion), class II malocclusion (distocclusion), and class III malocclusion (mesiocclusion). Class II malocclusion is of further two types: Class II div I and class II div II malocclusion. A considerable number of fixed and removable functional appliances are available for management of class II skeletal and dental malocclusion. ${ }^{2}$

Pancher $z^{3}$ reintroduced the Herbst appliance for the management of class II malocclusion. The Herbst appliance has become popular nowadays. Various studies have found this appliance favorable for the correction of the malocclusion. Apart from good results obtained from this appliance, it has resulted in various complications during the treatment as well as postoperatively. It includes soft tissue injuries, lower splint breakage, band fracture, crown fracture, screw loosening, rod distortion, and pivot breakage. ${ }^{4}$ Many studies by different authors 
have compared the complications of Herbst appliance with different designs. ${ }^{5,6}$

Herbst appliance has upper and lower components. It is attached to the teeth by stainless steel crowns with an expansion screw in the middle of the palate to help widen the upper jaw. A plunger extends from the upper component of the appliance to the lower component, and it permanently locates the lower jaw in a more anterior position, hence, it stimulates lower jaw growth and, therefore, decreases the overbite. ${ }^{7}$ Schioth et $\mathrm{al}^{8}$ conducted a study in which they studied the type and the prevalence of complications with the use of short and total metal splint. In his study, maxillary split debonding was the major complication.

This study was conducted to evaluate the complications occurring during treatment with this appliance.

\section{MATERIALS AND METHODS}

This study was conducted on the patients who got the treatment done from 2010 to 2015. Their records were taken and evaluated. It included 114 patients (61 males and 53 females). The sample was divided into two groups:

Group I: It includes 72 patients (40 males and 32 females). They were treated with the Herbst appliance with stainless steel crowns on the maxillary first molars and removable mandibular acrylic splint (RMS). A transpalatal arch connected the maxillary first molars.

Group II: It consisted of 42 patients (21 male and 21 female patients). These appliances were made in-house and consisted of four stainless steel crowns on the first upper and lower molars. A transpalatal arch connected the maxillary molars. A lingual arch with occlusal stops on the lower first premolars connected the lower first molars. It also included stainless steel wire made cantilever Herbst (HC). The lower axle was placed at the mesial end of the HC between the first and second premolars.

In this, either a Dentaurum type I or a propulsor mandibular abzil (PMA) telescopic system was used. For fixation, either a splint with stainless steel crowns or GripTite bands were used. The steel crowns and bands were cemented with Fuji Ortho LC.

Patient's edge-to-edge incisor relation was achieved by activating the Herbst appliance. It was continued for 15 months (10-18 months).

Patients were instructed to avoid eating hard or sticky foods. They were instructed to remove while brushing.

Any complications, such as soft tissue injuries, lower splint breakage, band fracture, crown fracture, screw loosening, rod distortion, and pivot breakage, were obtained from patients' records. Results obtained were subjected to statistical analysis using Statistical Package for the Social Sciences version 20; $\mathrm{p}<0.05$ was considered significant.

\section{RESULTS}

Table 1 shows the distribution of patients in groups according to the type, telescopic system, and fixation mode of the Herbst appliance. Group I consisted of 72 patients ( 40 males and 32 females). They were treated with the Herbst appliance with stainless steel crowns on the maxillary first molars and RMS. A transpalatal arch connected the maxillary first molars, in which telescopic system was PMA in 22 patients and Dentaurum in 50 patients. In group II, 28 patients were in PMA, and 14 patients were in Dentaurum telescopic system group. Mode of fixation was crown and band in group I and only crown in group II patients.

Table 2 shows a number of complications that arise due to Herbst appliances. It is either none or 1 to 2 complications.

Table 3 shows different complications of RMS and HC. Maximum complication was screw loosening in both groups.

\section{DISCUSSION}

Herbst appliance is a myofunctional appliance widely used for the treatment of Class II malocclusion. It is easy

Table 1: Distribution of groups according to the type, telescopic system, and fixation mode of the Herbst appliance

\begin{tabular}{lllll}
\hline \multicolumn{2}{c}{ Group I (RMS) (72) } & & \multicolumn{2}{c}{ Group II (HC) (42) } \\
\cline { 1 - 2 } Telescopic system & Fixation & & Telescopic system & Fixation \\
\hline PMA (22) & Crown (14) & & PMA (28) & Crown (28) \\
& Band (8) & & \\
Dentaurum (50) & Crown (38) & & Dentaurum (14) & Crown (14) \\
& Band (12) & & \\
\hline
\end{tabular}

Table 2: Complications arising with the use of different Herbst appliances

\begin{tabular}{|c|c|c|c|c|c|c|}
\hline \multirow[b]{2}{*}{ Complication } & \multicolumn{2}{|c|}{ Appliance } & \multicolumn{2}{|c|}{ Telescopic system } & \multicolumn{2}{|c|}{ Fixation } \\
\hline & RMS & $H C$ & Dentaurum & $P M A$ & Crown & Band \\
\hline None & 22 & 12 & 13 & 7 & 12 & 2 \\
\hline One or more & 50 & 30 & 42 & 24 & 82 & 18 \\
\hline
\end{tabular}

Table 3: Distribution of complication in both groups

\begin{tabular}{lll}
\hline Complication & RMS & HC \\
\hline Screw loosening & 12 & 8 \\
Crown debounce & 8 & 4 \\
Distortion of rod & 5 & 3 \\
Fracture of crown & 9 & 5 \\
Breakage of low splint & 7 & 2 \\
Breakage of pivot & 10 & 8 \\
Transpalatal arch breakage & 6 & 4 \\
Cantilever induces gingival lesion & 9 & 2 \\
Cantilever induces palatal lesion & 2 & 4 \\
Lesion on cheek due to long rod & 4 & 1 \\
Transpalatal arch breakage & 0 & 1 \\
\hline Total & 72 & 42 \\
\hline
\end{tabular}


to fabricate, which has increased its application. The Herbst appliance should be constructed with the mandible jumped anteriorly so as to achieve maximum results. Edge-to-edge position is preferred. A direct relationship existed between the amount of bite jumping at the start of treatment and the treatment effects on the occlusion and on mandibular growth., 10

In this study, we included 142 patients who visited from the year 2010 to 2015 for the treatment of Class II malocclusion. Out of all, 72 patients (40 males and 32 females) were treated with the Herbst appliance with stainless steel crowns on the maxillary first molars and RMS (group I). A transpalatal arch connected the maxillary first molars. Telescopic system was PMA in 22 patients and Dentaurum in 50 patients. Forty-two patients (21 males and 21 females) were those who received four stainless steel crowns on the first upper and lower molars. A transpalatal arch connected the maxillary molars. A lingual arch with occlusal stops on the lower first premolars connected the lower first molars. It also included stainless steel wire made HC (group II). The lower axle was placed at the mesial end of the $\mathrm{HC}$ between the first and second premolars. In group II, 28 patients were in PMA, and 14 patients were in Dentaurum telescopic system group. Mode of fixation was crown and band in group I and only crown in group II patients.

In this study, out of 72 RMS patients, 22 (30\%) had no complications. In HC patients, 12 (28\%) had no complication. Moro et al, ${ }^{4}$ in their study, observed 33\% complication in patients treated with $\mathrm{HC}$ bite jumper, while those who treated with RMS had no complications. Fifty (69\%) patients had one or more complications in group I, whereas $30(71 \%)$ patients showed complications in group II.

Depending on the telescopic unit used, 13 (27\%) Dentaurum and 7 (22\%) PMA had no complications at all, while 42 (76\%) patients using Dentaurum and 24 (77\%) patients using PMA had one or more complications.

In our study, mode of fixation was crown and band; $12(13 \%)$ patients using crown and $2(10 \%)$ patients using band had no complications; 82 (87\%) patients using crown and $18(90 \%)$ using band had one or more complications. Herbst with bands and $40 \%$ of patients who used a metallic splint had no complications during treatment.

Easy affordability, easy fitting, and self-ability to remove the splint to brush teeth have made this device favorable for patients. Moreover, mandibular splint shows decreased resistance. ${ }^{11}$ Apart from its usefulness, it has many shortcomings. In our study, we have noticed various complications, such as screw loosening, crown debounce, distortion of rod, fracture of crown, breakage of low splint, breakage of pivot, transpalatal arch breakage, cantilever inducing gingival lesion, cantilever inducing palatal lesion, lesion on cheek due to long rod, and transpalatal arch breakage.

Loosening of the screw was seen in 12 RMS and $8 \mathrm{HC}$ patients. Screw loosening may be explained by the fact that frequent removing of the lower splint for tooth brushing is the key reason for this complication. Moreover, its effectiveness also cannot be overruled. Other mostly seen complications in both groups were breakage of pivot, crown fracture, and crown debounce. It has been seen that most of the patients will observe complication with Herbst appliance. Hence, it is obvious duty of the dentist to be familiar with the dental changes occurring in treatment with Herbst appliance.

\section{CONCLUSION}

The authors concluded that PMA telescopic system is more efficient compared with Dentaurum. Complication resulting from Herbst appliance is independent of type of appliance used and mode of fixation.

\section{REFERENCES}

1. Angle EH. Classification of malocclusion. Dent Cosm 1899 Mar;41(3):241-264.

2. Profit, WR.; Fields, HW.; Sarver, DM. Contemporary orthodontics. St. Louis: Mosby; 2007.

3. Pancherz H. Treatment of class II malocclusions by jumping the bite with the Herbst appliance: a cephalometric investigation. Am J Orthod 1979 Oct;76(4):423-442.

4. Moro A, Janson G, Moresca R, de Freitas MR, Henriques JFC. Comparative study of complications during Herbst treatment with cantilever bite jumper and removable mandibular acrylic splint. Dent Press J Orthod 2011 Jan-Feb;16(1):29-31.

5. Hägg U, Tse EL, Rabie AB, Robinson W. A comparison of splinted and banded Herbst appliances: treatment changes and complications. Aust Orthod J 2002 Nov;18(2):76-81.

6. Sanden E, Pancherz H, Hansen K. Complications during Herbst appliance treatment. J Clin Orthod 2004 Mar;38(3):130-133.

7. Wieslander L. Intensive treatment of severe class II malocclusions with a headgear-Herbst appliance in the early mixed dentition. Am J Orthod 1984 Jul;86(1):1-13.

8. Schioth T, von Bremen J, Pancherz H, Ruf S. Complications during Herbst appliance treatment with reduced mandibular cast splints: a prospective, clinical multicenter study. J Orofac Orthop 2007 Jul;68(4):321-327.

9. Baccetti T, Franchi L, Stahl F. Comparison of 2 comprehensive class II treatment protocols including the bonded Herbst and headgear appliances: a double-blind study of consecutively treated patients at puberty. Am J Orthod Dentofacial Orthop 2009 Jun;135(6):698.e1-698.e10.

10. Jakobsone G, Latkauskiene D, McNamara JA Jr. Mechanisms of class II correction induced by the crown Herbst appliance as a single-phase class II therapy: 1 year follow-up. Prog Orthod 2013 Sep;14:27.

11. Silva JF, Gerszewski C, Moresca RC, Correr GM, Flores-Mir C, Moro A. Retrospective study of clinical complications during orthodontic treatment with either a removable mandibular acrylic splint Herbst or with a cantilever Herbst. Angle Orthod 2015 Jan;85(1):64-71. 